NOTE

\title{
Predicting abundance-body mass relationships in benthic infaunal communities
}

\author{
T. A. Dinmore*, S. Jennings \\ Centre for Environment, Fisheries and Aquaculture Science, Lowestoft Laboratory, Lowestoft, NR33 OHT, UK
}

\begin{abstract}
The body size composition of benthic communities is commonly described using abundance-body mass relationships (size spectra). We tested whether the slopes of these relationships in a central North Sea infaunal community could be predicted from the energy available to different size-classes of animals. The results showed that the observed slopes were consistent with predictions of slope based on available energy at mass, where available energy was calculated from empirical measurements of trophic level (using nitrogen stable isotope analysis) and estimated trophic transfer efficiency. If our preliminary findings prove to apply more widely, then our macroecological approach may be refined to validate size-based models of community structure to explain regional differences in size structure and to underpin the development of new disturbance indicators.
\end{abstract}

KEY WORDS: Abundance-body mass relationships $\cdot$ Macroecology $\cdot$ Energetic equivalence $\cdot$ Size spectra $\cdot$ Benthic invertebrates $\cdot$ Stable isotope analysis $\cdot$ Trophic structure

\section{INTRODUCTION}

Abundance-body mass relationships (size spectra) are a conservative property of many benthic communities (Warwick 1984), exhibiting more stability in space and time than the abundance of component species (Schwinghamer 1981). An understanding of the factors responsible for shaping abundance-body mass relationships in the absence of human impacts has applied significance, since changes in these relationships may be a good indicator of the effects of pollution or physical disturbance (Schwinghamer 1988, Duplisea et al. 2002).

Some macroecological theory focuses on predicting the form of abundance-body mass relationships (Brown \& West 2000, Gaston \& Blackburn 2000). In communities sharing a common energy source, for example, the energetic equivalence hypothesis predicts that numerical abundance $(N)$ and biomass abundance $(B)$ scale with body mass $(M)$ as $M^{-0.75}$ and $M^{0.25}$ respectively (Damuth 1981, Belgrano et al. 2002). However, since energy transfer in food chains is inefficient and since the lengths of food chains supporting individuals will vary, scalings predicted by the energetic equivalence hypothesis are not observed in many animal communities.

In size-structured food webs, where larger predators eat smaller prey, available energy $(E)$ decreases with increasing mass as a function of the mean predator prey mass ratio $(P P M R)$ and trophic transfer efficiency (TE) (Brown \& Gillooly 2003). Thus, observed scalings of abundance with $M$ in size-structured food webs will be steeper than predicted by the energy equivalence hypothesis.

For communities in which trophic level increases continuously with $M$, the Brown \& Gillooly (2003) approach can be formalised whereby, for a given $T E$ and $P P M R$, the expected scaling of $E$ with $M$ is

$$
E \propto M^{\log _{10} T E / \log _{10} P P M R}
$$

where $P P M R$ is defined from the slope $(b)$ of the relationship between trophic level $(y)$ and $\log _{10} M(x)$ 
$\left(P P M R=10^{(1 / b)}\right)($ Jennings \& Mackinson 2003) and TE is the efficiency with which prey production is converted to predator production

$$
T E=P_{\mathrm{c}} / P_{\mathrm{p}}
$$

where $P_{\mathrm{c}}$ is predator production and $P_{\mathrm{p}}$ is prey production (e.g. Ware 2000).

From Eq. (1) and assuming that the scaling of $N$ and $B$ with $M$ within an infinitely small increment in body mass (and hence trophic level) can be predicted by the energetic equivalence hypothesis $\left(N \propto M^{-0.75}\right.$ and $B \propto M^{0.25}$ respectively), the predicted scaling of $N$ and $M$ is

$$
N \propto M^{\log _{10} T E / \log _{10} P P M R} \times M^{-0.75}
$$

and the scaling of $B$ and $M$ is

$$
B \propto M^{\log _{10} T E / \log _{10} P P M R} \times M^{0.25}
$$

One recent analysis suggests that the scaling of abundance and body mass in a size-structured open sea food web was consistent with the predictions of the formalised Brown \& Gillooly (2003) model (Jennings \& Mackinson 2003).

Benthic infaunal communities have characteristic abundance-body mass relationships, but these communities are only one part of the complete food web. Unlike the complete food web, the size structure of infaunal communities does not primarily reflect sizebased predation, since many of the largest animals (e.g. bivalve molluscs, burrowing echinoderms) feed at lower trophic levels than some of the smaller animals (e.g. predatory polychaete worms). However, the benthic infaunal community is effectively sustained by a single energy source which reaches the seafloor as phytoplankton or detritus (e.g. Künitzer et al. 1992).

Here, we test whether slopes of abundance-body mass relationships for a benthic infaunal community can be predicted from the energy available to different size-classes of animals. Energy availability at size is calculated from the scaling of $E$ with $M$, based on estimated trophic level at size (from nitrogen stable isotope analysis) and TE.

\section{MATERIALS AND METHODS}

The size structure of the benthic infaunal community was described at 13 sites in an area of the central North Sea bounded by latitude $54^{\circ} 00^{\prime} \mathrm{N}$ to $54^{\circ} 30^{\prime} \mathrm{N}$ and longitude $00^{\circ} 30^{\prime} \mathrm{E}$ to $01^{\circ} 20^{\prime} \mathrm{E}$. Trawling did not have a detectable direct effect on the size or trophic structure of the benthic infaunal community at these sites (e.g. Jennings et al. 2001 and related papers). Depth at the sites ranged from 40 to $65 \mathrm{~m}$ and sediment consisted primarily of sand (mean particle diameters 0.250 to
$0.350 \mathrm{~mm}$; British Geological Survey unpubl.). For further details of the sites see Jennings et al. (2001).

Infaunal invertebrates (defined as those species that live predominantly covered by the substrate) were sampled with an anchor dredge (Kaiser et al. 2000) from 22 November to 8 December 1999. A total of 3 randomly located replicate tows of $1 \mathrm{~min}$ duration were made at each site, a box of $1 \mathrm{n}$ mile north-south by $1 \mathrm{n}$ mile east-west, and a sub-sample of $0.2 \mathrm{~m}^{3}$ sediment was removed from each sample. This was sieved through $1 \mathrm{~mm}^{2}$ mesh and all free-living infaunal species retained on the mesh were identified, weighted and allocated to $\log _{2}$ wet weight size-classes. To obtain tissue for stable isotope analysis, all animals from the same size-class in each of the 3 replicate samples were pooled and homogenised in an electric blender, usually with added water, to produce a thoroughly mixed suspension that poured smoothly. Approximately $7 \mathrm{ml}$ of this suspension was retained and frozen to $-20^{\circ} \mathrm{C}$ in a glass vial.

The frozen homogenised tissue was freeze dried and crumbled or ground to a fine powder (particle diameter $<60 \mu \mathrm{m})$. Samples of powder (1 mg) were weighed into a tin capsule, and the ${ }^{15} \mathrm{~N}$ composition was determined using continuous flow isotope ratio mass spectrometry (PDZ - Europa Integra - CN system). To calibrate the system and compensate for drift, 2 samples of reference material (a standard mix of ammonium sulphate and beet sugar) were analysed after every 5 tissue samples. The ${ }^{15} \mathrm{~N}$ composition was expressed in conventional delta notation $\left(\delta^{15} \mathrm{~N}\right)$, relative to the abundance of ${ }^{15} \mathrm{~N}$ in atmospheric $\mathrm{N}_{2}$. Experimental precision was $0.1 \%$ o (SD of $\delta^{15} \mathrm{~N}$ for replicates of reference material).

Wet mass was converted to ash free dry mass (AFDM) for all faunal groups (bivalves, annelida, crustaceans, echinoderms, sipunculids, nemerteans and anemones [actinaria]) using the conversion factors in Brey (2001: available at www.awi-bremerhaven.de/Benthic/ Ecosystem/FoodWeb/Handbook/main.html). To express $B$ and $N$ as $\mathrm{g} \mathrm{m}^{-2}$ and numbers $\mathrm{m}^{-2}$ respectively we assumed that the $0.2 \mathrm{~m}^{3}$ subsample was equivalent to a sampled area of $0.2 \mathrm{~m}^{3}$, although this assumption had no effect on the calculated slopes of abundance-body mass relationships. Since animals had to be sorted by wet mass for stable isotope analysis, we recalculated the midpoints of $M$ classes as AFDM, based on the relative biomass of animal groups in the sample and the relationships between wet mass and AFDM for those groups. To produce abundance-body mass relationships for each site, individual invertebrates were assigned to $\log _{2}$ AFDM classes and total AFDM $(B)$ or $(N)$ in each class was calculated. Slopes $(b)$ of abundance-body mass relationships were determined from the linear relationships: 
and

$$
\log _{10} N=a_{N}+b_{N}\left(\log _{10} M\right)
$$

$$
\log _{10} B=a_{B}+b_{B}\left(\log _{10} M\right)
$$

with $\log _{2} M$ classes converted to $\log _{10}$.

The mean rate of change in trophic level with $M$ was calculated as the slope of the relationship between $\delta^{15} \mathrm{~N}(y)$ and $\log _{10} M(x)$, based on an assumed mean fractionation of $3.4 \% \delta^{15} \mathrm{~N}$ per trophic level (Post 2002). We ran sensitivity analyses to assess the effect of fractionation assumptions on the results. The scaling of $E$ with $M$ was calculated as $\log _{10} T E /(3.4 /$ slope). Following Eq. (3), the predicted scaling of $N$ with $M$ was

$$
N \propto M^{\log _{10} T E /\left(3.4 / b_{N}\right)} \times M^{-0.75}
$$

and following Eq. (4) the scaling of $B$ with $M$ was

$$
B \propto M^{\log _{10} T E /\left(3.4 / b_{B}\right)} \times M^{0.25}
$$

$T E$ was assumed to be 0.125 (e.g. data compilation in Ware [2000]) although we also ran sensitivity analyses to assess the effects of changes in TE.

\section{RESULTS AND DISCUSSION}

The trophic level $\left(\delta^{15} \mathrm{~N}\right)$ of the benthic infaunal community decreased with increasing $M$ (Fig. 1). The slope of the relationship between $\delta^{15} \mathrm{~N}$ and $M$ was -1.07 . Thus, $E \propto M^{0.28}, B \propto M^{0.53}$ and $N \propto M^{-0.47}$ when $T E=$ 0.125 and fractionation $=3.4 \% \delta^{15} \mathrm{~N}$ per trophic level. The scalings were relatively insensitive to potential errors in the assumed fractionation of $\delta^{15} \mathrm{~N}$ or TE (Fig. 2).

The observed scalings of $B$ and $N$ with $M$ were 0.48 and -0.54 respectively (Fig. 3 ). These were not significantly different from the predicted scalings of $B(0.53)$ and $N(-0.47)$. Predicted scalings based on energetic equivalence also fell within $95 \%$ confidence limits for the regression (Fig. 3), but were not as close to the observed values as the scalings predicted when we did account for trophic structure. We suggest that the predicted relationships were more consistent with theo-

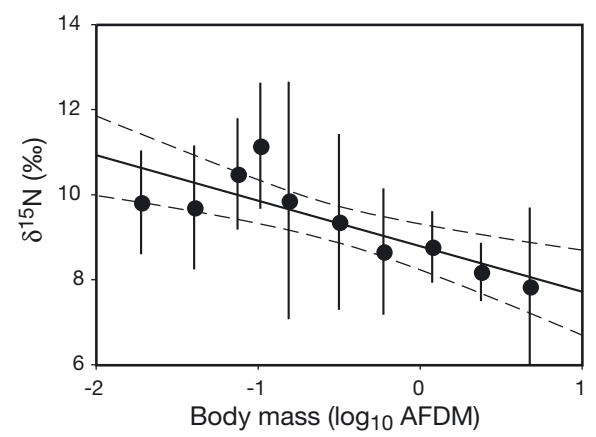

Fig. 1. Relationship between $\delta^{15} \mathrm{~N}$ and body mass $(M)$ in the benthic infaunal community. $M$ is expressed as $\log _{10}$ ash free dry mass (AFDM). Confidence limits (95\%) for the fitted relationship are shown. Vertical bars are \pm SD
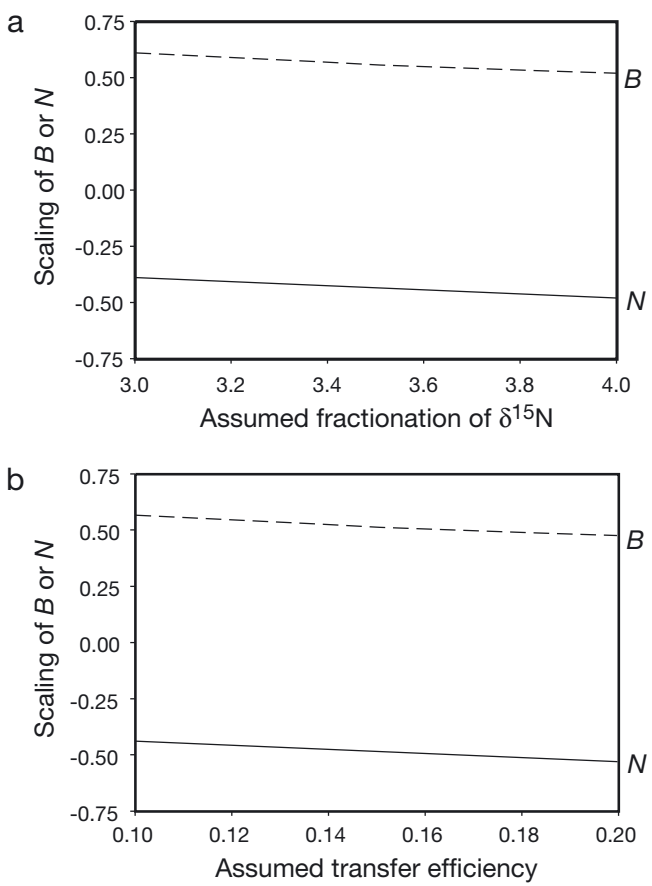

Fig. 2. Predicted scalings of $B$ and $N$ calculated from the slopes of relationships between $\log _{10} B$ (biomass abundance) or $\log _{10} N$ (numerical abundance) and $\log _{10} M$ (body mass) as a function of (a) the assumed fractionation of $\delta^{15} \mathrm{~N}$ and

(b) assumed transfer efficiency

retical predictions when we accounted for trophic structure because larger individuals tended to feed at lower trophic levels and relatively more energy would have been available to them.
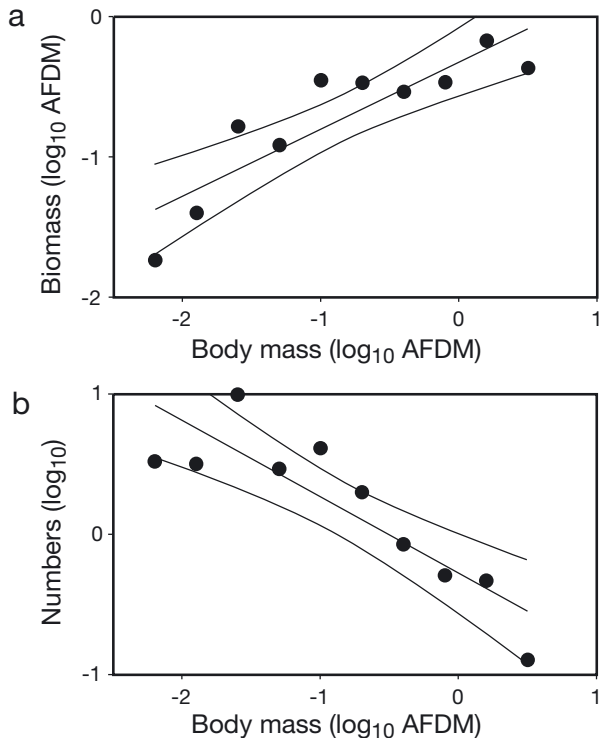

Fig. 3. (a) Biomass abundance (B) and (b) numerical abundance $(N)$ versus body mass $(M)$ relationships for the benthic infaunal community plotted on a log scale. $M$ is expressed as $\log _{10}$ ash free dry mass (AFDM). Confidence limits (95\%) for the fitted relationship are shown 
The analysis suggests that we can modify theory that is most usefully applied to the prediction of abundance-body mass relationships in food webs to predict these relationships in a benthic infaunal community. The analysis is probably robust because the benthic infaunal community is dependent on a single energy source. The approach used in our analysis would not be expected to work when applied to taxonomically defined subsets of the food web that received energy inputs from many sources.

The formalised Brown \& Gillooly (2003) model was previously used to predict abundance-body mass relationships in unexploited food webs (Jennings \& Blanchard 2004). Such predictions provide a baseline for assessing the magnitude and scale of human impacts. The predictions can be made because $P P M R$ is largely unaffected by observed levels of disturbance (in this case fisheries exploitation) and thus an estimate of $P P M R$ from an exploited community can be used to model abundance-body mass relationships in the unexploited community (Jennings \& Blanchard 2004). In the benthic infaunal community we considered, which is a subset of the real food web, the energy available to animals in different body size-classes is a function of the types of animals present in the sizeclasses and not PPMR. Since disturbance has the potential to modify both size and trophic structure of the benthic community, knowledge of the trophic structure of a disturbed community is unlikely to provide a basis for predicting abundance-body mass relationships in the absence of disturbance. The only exception to this rule would be a community in which trophic level did not change with body size. In this case, exploitation would not change trophic structure and the unexploited abundance-body mass relationship might be predicted from the energetic equivalence hypothesis.

Our results suggest that the slopes of benthic infaunal size spectra are consistent with theoretical predictions based on trophic structure and transfer efficiency. This is a preliminary test, based on data collected as part of an earlier study, and we hope to gather new data to validate and refine the approach and to assess the significance of non-linearities in the spectra. The approach has potential application as a tool for validating other size-based models of benthic community structure, for explaining regional differences in the size structure of benthic infaunal communities and for underpinning the development of new disturbance indicators.

Editorial responsibility: Otto Kinne (Editor), Oldendorf/Luhe, Germany
Acknowledgements. We thank Brian Edwards, Roger Flatt, Dave Palmer, Michaela Schratzberger, Christie Stewart, Peter Walker and the officers and crew of RV 'Corystes' for their efforts in the field, Sam Barker and Rowan White for the stable isotope analyses and Nick Dulvy and 3 anonymous reviewers for helpful comments on the text. The DEFRA MF07 'Impacts of fishing' programme (MF0731, MF0737) funded this research, with additional funding and support from SCOR IOC NMFS WG 119.

\section{LITERATURE CITED}

Belgrano A, Allen AP, Enquist BJ, Gillooly JF (2002) Allometric scaling of maximum population density: a common rule for marine phytoplankton and terrestrial plants. Ecol Lett 5:611-613

Brown JH, Gillooly JF (2003) Ecological food webs: Highquality data facilitate theoretical unification. Proc Natl Acad Sci USA 100:1467-1468

Brown JH, West GB (2000) Scaling in biology. Oxford University Press, Oxford

Damuth J (1981) Population density and body size in mammals. Nature 290:699-700

Duplisea DE, Jennings S, Warr KJ, Dinmore T (2002) A sizebased model of the impacts of bottom trawling on benthic community structure. Can J Fish Aquat Sci 59:1785-1795

Gaston KJ, Blackburn TM (2000) Pattern and process in macroecology. Blackwell Science, Oxford

Jennings S, Blanchard JL (2004) Fish abundance with no fishing: predictions based on macroecological theory. J Anim Ecol 73:632-642

Jennings S, Mackinson S (2003) Abundance-body mass relationships in size-structured food webs. Ecol Lett 6:971-974

Jennings S, Pinnegar JK, Polunin NVC, Warr KJ (2001) Impacts of trawling disturbance on the trophic structure of benthic invertebrate communities. Mar Ecol Prog Ser 213:127-142

Kaiser MJ, Ramsay K, Richardson CA, Spence FE, Brand AR (2000) Chronic fishing disturbance has changed shelf sea benthic community structure. J Anim Ecol 69:494-503

Künitzer A, Basford D, Craeymeersch JA, Dewarumez JM and 10 others (1992) The benthic infauna of the North Sea: species distribution and assemblages. ICES J Mar Sci 49: $127-143$

Post DM (2002) Using stable isotopes to estimate trophic position: models, methods and assumptions. Ecology 83: 703-718

Schwinghamer P (1981) Characteristic size distributions of integral benthic communities. Can J Fish Aquat Sci 38: 1255-1263

Schwinghamer P (1988) Influence of pollution along a natural gradient and in a mesocosm experiment on biomass-size spectra of benthic communities. Mar Ecol Prog Ser 46: 199-206

Ware DM (2000) Aquatic ecosystems: properties and models. In: Harrison PJ, Parsons TR (eds) Fisheries oceanography: an integrative approach to fisheries ecology and management. Blackwell Science, Oxford, p 161-194

Warwick RM (1984) Species size distributions in marine benthic communities. Oecologia 61:32-41

Submitted: November 11, 2003; Accepted: June 29, 2004

Proofs received from author(s): July 12, 2004 